\title{
ANÁLISE DO DIREITO À AUTODETERMINAÇÃO DAS COMUNIDADES QUILOMBOLAS NO JULGAMENTO DA ADI No 3239/2004 NO STF: ENTRE O DEGREDO, O ESQUECIMENTO E O DESCONHECIMENTO JURÍDICO
}

\section{Ricardo Vinhaes Maluf Cavalcante* Cássius Guimarães Chai ${ }^{* *}$}

\begin{abstract}
Resumo: O presente artigo busca refletir se, no Brasil, o Supremo Tribunal Federal - STF tem apresentado posicionamento protetivo quanto ao direito das comunidades quilombolas, especialmente quanto ao direito à autodeterminação garantido pela Constituição Federal de 1988 e pela Convenção $n^{\circ}$. 169 da Organização Internacional do Trabalho - OIT. Tem-se como objeto de análise o julgamento da Ação Direta de Inconstitucionalidade no . 3239/04 que questionava a constitucionalidade do Decreto $\mathrm{n}^{\mathrm{o}} 4.887 / 03$ que trata da identificação, reconhecimento, delimitação, demarcação e titulação das terras das comunidades quilombolas.
\end{abstract}

Palavras-chave: Comunidades quilombolas; Autodeterminação; ADI 3239/04/STF; Decreto $n^{\circ}$ 4.887/03; Marco Temporal.

\section{ANALYSIS OF THE RIGHT TO SELF-DETERMINATION OF QUILOMBOLAS COMMUNITIES IN THE JUDGMENT OF ADI No 3239/2004 IN STF: BETWEEN EXILE, OBLIVION AND JURIDICAL NONRECOGNITION}

\begin{abstract}
The present article aims to reflect if, in Brazil, the Federal Supreme Court (STF) has presented a protective position about the right of quilombolas communities, especially regarding the right to self-determination guaranteed by the 1988 Federal Constitution and by Convention $\mathrm{n}^{\mathrm{o}} .169$ of the International Labor Organization - ILO. The object of analysis is the judgment of the Direct Unconstitutionality Action $\mathrm{n}^{\circ}$. 3239/04 that questioned the constitutionality of Decree $n^{\circ} .4 .887 / 03$ regarding the identification, recognition, delimitation, demarcation and titling of quilombolas communities' lands.
\end{abstract}

Keywords: Quilombolas communities; Self-determination; ADI 3239/04/STF; Decree $\mathrm{n}^{\circ}$ 4.887/03; Temporal limit.

\footnotetext{
* Mestrando em Direito pelo Programa de Pós-Graduação em Direito e Instituições do Sistema de Justiça da Universidade Federal do Maranhão (PPGDIR/UFMA). Graduado em Direito pela Universidade Federal do Maranhão (UFMA). E-mail: ricardovmc@hotmail.com. Lattes: http://lattes.cnpq.br/3333890502662570. Endereço Postal: Rua Piauí, nº 146, Chácara Brasil, Turu, CEP 65066-873, São Luís, Maranhão.

'** Doutor em Direito pela Universidade Federal de Minas Gerais (UFMG) e pela Cardozo School of Law Yeshiva University. Mestre em Direito pela Universidade Federal de Minas Gerais (UFMG). Especialista em Direito, Estado e Sociedade pela Universidade Federal de Santa Catarina (UFSC). Graduado em Direito pela Universidade Federal do Maranhão (UFMA). Membro do Ministério Público do Estado do Maranhão. Professor Associado da Universidade Federal do Maranhão (UFMA). Coordenador do Grupo de Pesquisa Cultura, Direito e Sociedade (UFMA). E-mail: cassiuschai@gmail.com. Lattes: http://lattes.cnpq.br/7954290513228454. Endereço Postal: Sede das Promotorias de Justiça da Capital - Av. Prof. Carlos Cunha, s/n, Jaracaty, CEP 65076820, São Luís, Maranhão.
} 


\section{INTRODUÇÃO}

Após séculos de dominação, exploração e extermínio, em Estados violentamente construídos sem participação e alheios às vontades dos povos indígenas e comunidades tradicionais ${ }^{1}$, estes, por meio de movimentos sociais e de entidades e organizações nacionais e internacionais, têm lutado nas últimas décadas por seus direitos como sujeitos coletivos, detentores de uma identidade própria e diferenciada.

As lutas e reinvindicações dos povos e comunidades têm repercutido em transformações e no reconhecimento dos seus direitos tanto na esfera interna dos Estados, quanto na internacional. Atualmente conta-se com importantes instrumentos legais e judiciais internacionais, como também nacionais, de proteção dos povos e comunidades.

Destaca-se a Convenção $n^{0} .169$ da Organização Internacional do Trabalho - OIT, que reconhece o direito à autodeterminação dos povos, a proteção dos territórios, garante o autogoverno, direitos políticos, de participação, além de outros. Enfatiza-se também, no âmbito nacional, a Constituição Federal de 1988, que assim como a Convenção $n^{\circ}$. 169, consolida a autodeterminação, a defesa dos diferentes modos de viver, fazer e criar, as identidades, a pluralidade cultural, reconhece as comunidades quilombolas, os povos indígenas, dentre outros, como se verá.

Nesse sentido, o presente artigo científico busca refletir se, no Brasil, o Supremo Tribunal Federal - STF, a mais alta instância do sistema judiciário brasileiro, tem apresentado posicionamento protetivo especificamente quanto aos direitos das comunidades quilombolas, em conformidade com a autodeterminação e demais dispositivos arduamente conquistados pelas lutas dos movimentos sociais.

Para tanto, tem-se como objeto de estudo o julgamento da Ação Direta de Inconstitucionalidade - ADI $\mathrm{n}^{\circ}$. 3239/2004, que foi finalizada em fevereiro de 2018, e questionava a Constitucionalidade do Decreto $\mathrm{n}^{\mathrm{o}}$. 4.887/2003, que regulamenta o procedimento para identificação, reconhecimento, delimitação, demarcação e titulação das

\footnotetext{
${ }^{1}$ Esclarece-se que a Convenção $n^{\circ} .169$ da OIT, que é considerada um dos principais tratados internacionais de proteção dos povos, utiliza o termo povos indígenas e tribais. Todavia, a Convenção não limitou taxativamente quais seriam estes povos, pois tem o objetivo de abarcar sob a sua proteção os grupos tradicionais que vivem em todos os Estados (TOMEI; SWEPSTON, 1999). Sendo assim, no Brasil, onde não há povos tribais no sentido estrito do termo, considera-se que a Convenção $n^{\circ}$. 169 incide sobre as comunidades tradicionais, como os quilombolas, as quebradeiras de coco, os faxinalenses, dentre outros (SHIRAISHI NETO, 2014b).
} 
terras ocupadas por remanescentes das comunidades dos quilombos de que trata o art. 68 do Ato das Disposições Constitucionais Transitórias - $\mathrm{ADCT}^{2}$.

Ressalta-se que se encontra em jogo no referido julgamento, dessa maneira, o reconhecimento das comunidades quilombolas, de seus territórios, e assim, a continuidade das suas identidades.

\section{IDENTIDADE QUILOMBOLA: ENTRE O DEGREDO, O ESQUECIMENTO E O DESCONHECIMENTO JURÍDICO}

Analisar-se-á no presente tópico as transformações do direito e da definição de quilombo que vêm se desenrolando desde 1740 até os dias atuais. Observar-se-á como, do degredo, os quilombolas passaram por um período de esquecimento, invisibilidade jurídica, até o desconhecimento jurídico, com o estabelecimento de uma definição insuficiente quanto ao atendimento de seus interesses. Enfatiza-se, entretanto, que deve haver a prevalência do direito à autodeterminação das comunidades quilombolas, como se verificará a seguir.

\subsection{O DEGREDO}

Faz-se importante entender primeiramente que o conceito de quilombo que foi definido em 1740 pelo Conselho Ultramarino, e correspondia a: "toda habitação de negros fugidos, que passem de cinco, em parte despovoada, ainda que não tenham ranchos levantados e nem se achem pilões nele" (ALMEIDA, 2002, p. 47), permeou por muito tempo o imaginário da sociedade sobre o que seria o quilombo.

Percebe-se que esse conceito possuía cinco elementos essenciais: a questão da fuga ("habitação de negros fugidos"), a quantidade mínima de negros ("passem de cinco"), o local isolado e de difícil acesso ("em parte despovoada"), a existência de moradia no local ("ainda que não tenham ranchos levantados") e a capacidade de subsistência ("nem se achem pilões nele"). Esses elementos denotam uma ideia de que os quilombolas estariam isolados da civilização e adstritos em sua capacidade de produzir para sua subsistência. Revelam também

\footnotetext{
${ }^{2}$ CF/88. Art. 68 do ADCT. Aos remanescentes das comunidades dos quilombos que estejam ocupando suas terras é reconhecida a propriedade definitiva, devendo o Estado emitir-lhes os títulos respectivos.
} 
a criminalização dos quilombos, como negros que fugiram das suas responsabilidades para com os seus senhores (ALMEIDA, 1999).

Contudo, vem-se apontar que esse é o conceito de quilombo que se enraizou, até os dias atuais, na mentalidade da sociedade e dos operadores do direito; que ao se questionar acerca do conceito de quilombo, ainda há a relação deste à uma localidade isolada e mais ligada à natureza, como contraponto à ideia de civilização, e há também a ideia de fuga do trabalho que realizavam (ALMEIDA, 1999).

Observa-se, por outo lado, que tal entendimento, incrustado no inconsciente das pessoas, dificulta o amplo reconhecimento dos direitos dos quilombolas, em especial o direito à terra. Tanto que tramitou, de 2004 a 2018, no Supremo Tribunal Federal, a referida Ação Direta de Inconstitucionalidade $n^{\circ}$. 3239, que questionou a validade do Decreto $n^{\circ} .4 .887 / 03^{3}$. Portanto, compreende-se ser fundamental analisar criticamente a ideia que se tem de quilombo como algo que está de fora, "isolado, para além da civilização e da cultura, confinado numa suposta autossuficiência e negando a disciplina do trabalho" (ALMEIDA, 2002, p. 49).

\subsection{O ESQUECIMENTO}

Após a abolição da escravidão, por considerar que a partir desse momento não haveriam mais quilombos, já que não existiriam mais escravos e tampouco a fuga destes, ocorreu um longo período de verdadeiro silêncio de tutela constitucional sobre os quilombolas. O entendimento era que ocorreria a sua extinção natural (ALMEIDA, 2002; LITLE, 2002).

Desse modo, os quilombolas, do degredo, vistos como criminosos que fugiam das suas obrigações, passaram a uma total invisibilidade jurídica que lhes furtava $o$ reconhecimento enquanto sujeitos coletivos de direito e o controle sobre seus territórios aos quais tradicionalmente se vinculavam (BANDEIRA, 1991).

No entanto, como já mencionado, com a intensificação das lutas dos movimentos sociais ocorrida a partir da década de 70 (ALMEIDA, 2004) e, mais especificamente,

\footnotetext{
${ }^{3}$ Como citado, o Decreto $\mathrm{n}^{\circ}$. 4.887/03 regulamenta o procedimento para identificação, reconhecimento, delimitação, demarcação e titulação das terras ocupadas por remanescentes das comunidades dos quilombos de que trata o art. 68 do Ato das Disposições Constitucionais Transitórias.
} 


\section{ANÁLISE DO DIREITO À AUTODETERMINAÇÃO DAS COMUNIDADES QUILOMBOLAS NO JULGAMENTO DA ADI № 3239/2004 NO STF: ENTRE O DEGREDO, O ESQUECIMENTO E O DESCONHECIMENTO JURÍDICO}

"com o surgimento de uma consciência negra como parte de um processo maior de organização política a partir da década de 1980, os quilombos rapidamente passaram a gozar de uma nova visibilidade política" (LITLE, 2002, p. 14).

Com o advento da Constituição Federal de 1988 ocorreu o rompimento da invisibilidade jurídica na qual, até então, os quilombolas se encontravam. A Carta Magna, de forma inovadora, estabeleceu o direito à diferença, à diversidade cultural, e uma nova relação jurídica entre o Estado e os povos indígenas e comunidades tradicionais (ALMEIDA, 2004). Foram reconhecidas as suas identidades, os seus modos de criar, fazer e viver e o direito de permanecerem como tais, de darem continuidade aos seus costumes e tradições.

Em vários dispositivos, a Constituição Federal de 1988 menciona as identidades dos povos e comunidades ${ }^{4}$ e, no preâmbulo, é garantida uma "sociedade fraterna, pluralista e sem preconceitos" (SOUZA FILHO, 2016). Nessa perspectiva, interpreta-se que a CF/88, de forma pluralista, reconhece os diferentes povos e comunidades, ainda que não tenham sido explicitamente citados no texto da constituição (SHIRAIHI NETO, 2014b).

Dentre os grupos que foram explicitamente mencionados na $\mathrm{CF} / 88$, encontram-se os quilombolas, referenciados no $\S 5^{\circ}$ do artigo $216^{5}$ e no artigo 68 do ADCT. Este último expõe que "aos remanescentes das comunidades dos quilombos que estejam ocupando suas terras é reconhecida a propriedade definitiva, devendo o Estado emitir-lhes os títulos respectivos".

\subsection{O DESCONHECIMENTO JURÍDICO}

\footnotetext{
${ }^{4}$ Dentre outros: Art. 215. O Estado garantirá a todos o pleno exercício dos direitos culturais e acesso às fontes da cultura nacional, e apoiará e incentivará a valorização e a difusão das manifestações culturais. $\S 1^{\circ} \mathrm{O}$ Estado protegerá as manifestações das culturas populares, indígenas e afro-brasileiras, e das de outros grupos participantes do processo civilizatório nacional. [...].

Art. 216. Constituem patrimônio cultural brasileiro os bens de natureza material e imaterial, tomados individualmente ou em conjunto, portadores de referência à identidade, à ação, à memória dos diferentes grupos formadores da sociedade brasileira, nos quais se incluem: I - as formas de expressão; II - os modos de criar, fazer e viver; [...].

Art. 231. São reconhecidos aos índios sua organização social, costumes, línguas, crenças e tradições, e os direitos originários sobre as terras que tradicionalmente ocupam, competindo à União demarcá-las, proteger e fazer respeitar todos os seus bens.

Art. 54. ADCT. Os seringueiros recrutados nos termos do Decreto-Lei n ${ }^{0}$ 5.813, de 14 de setembro de 1943, e amparados pelo Decreto-Lei $n^{\circ}$ 9.882, de 16 de setembro de 1946, receberão, quando carentes, pensão mensal vitalícia no valor de dois salários mínimos. $\S 1^{\circ} \mathrm{O}$ benefício é estendido aos seringueiros que, atendendo a apelo do Governo brasileiro, contribuíram para o esforço de guerra, trabalhando na produção de borracha, na Região Amazônica, durante a Segunda Guerra Mundial. § $2^{\circ}$ Os benefícios estabelecidos neste artigo são transferíveis aos dependentes reconhecidamente carentes. [...].

5 Art. 216, § $5^{\circ}$ Ficam tombados todos os documentos e os sítios detentores de reminiscências históricas dos antigos quilombos $[\ldots]$.
} 
Compreende-se, entretanto, que o direito previsto no art. 68 do ADCT representa uma perspectiva vinculada à concepção estruturada no passado sobre os quilombos concepção esta que, dessa forma, perdura ao longo do tempo - e não reflete as especificidades das comunidades. O próprio termo remanescente tem um significado restrito, refere-se ao que sobrou, como se outros quilombos não pudessem surgir.

Como explica Almeida (2002, p. 53):

\begin{abstract}
Constata-se um silêncio nos textos constitucionais sobre a relação entre os exescravos e a terra, principalmente no que tange ao símbolo de autonomia produtiva representado pelos quilombos. E quando é mencionado na Constituição de 1988, 100 anos depois, o quilombo já surge como sobrevivência, como "remanescente". Reconhece-se o que sobrou, o que é visto como residual, aquilo que restou, ou seja, aceita-se o que já foi. Julgo que, ao contrário, se deveria trabalhar com o conceito de quilombo considerando o que ele é no presente. Em outras palavras, tem que haver um deslocamento. Não é discutir o que foi, e sim discutir o que é e como essa autonomia foi sendo construída historicamente.
\end{abstract}

Assim, o art. 68 do ADCT, ao tentar reparar uma injustiça histórica, acabou restringindo a aplicação de um direito essencial, que é o direito à terra - "esquecido" durante muito tempo - apenas às comunidades que se enquadravam na perspectiva embasada no passado sobre o que seria um quilombo. Enfatiza-se que o conceito de quilombo, nesses termos, ficou "frigorificado", entrelaçado ao que foi, e não ao que é hoje (ALMEIDA, 2002). Dessa maneira, verifica-se que há a preocupação em levantar comprovações sobre a data da origem dos quilombos como remanescentes de ex-escravos fugidos e pouco se discute sobre as suas identidades.

Shiraishi Neto (2014a), nesse sentido, adverte que é arriscado tratar as questões envolvendo os quilombolas sob a ótica do Direito Agrário, que tem um caráter excludente, orientado para a proteção de alguns grupos em detrimentos de outros. Alerta também que as políticas definidas pelo Estado para o reconhecimento dos quilombolas acabam encontrando obstáculos ao serem efetivadas com base em categorizações externas a estes, a partir da noção preconcebida sobre o que é um quilombo.

\title{
2.4 A QUEBRA DE PARADIGMAS E A AUTODETERMINAÇÃO
}




\section{ANÁLISE DO DIREITO À AUTODETERMINAÇÃO DAS COMUNIDADES QUILOMBOLAS NO JULGAMENTO DA ADI № 3239/2004 NO STF: ENTRE O DEGREDO, O ESQUECIMENTO E O DESCONHECIMENTO JURÍDICO}

Para além desse enlace engessado no que foi, Almeida (2002), a fim de provocar uma reflexão crítica sobre a questão, pondera se não podem ser considerados quilombolas, por exemplo, além dos descendentes dos escravos fugidos, os escravos que fugiram mas foram recapturados, os escravos que não conseguiram fugir pois tinham que ficar para ajudar aqueles que conseguiram, os escravos que não precisaram fugir em função de várias situações de aquilombamento - com a crise económica na colonização houve concessão de terras, pelos senhores, aos negros para que pudessem tirar de lá o seu próprio sustento -, dentre outros.

Ademais, Litle (2002) também observa que, ao contrário do que se extrai do termo "remanescente das comunidades dos quilombos", após a Constituição de 1988, em um processo de etnogênese, o número de comunidades quilombolas cresce significativamente. Acerca do assunto, reforça-se que, antes da $\mathrm{CF} / 88$, ser considerado quilombola tinha uma conotação pejorativa, negativa, já que o termo conceituava os negros fugidos do trabalho. Eram então considerados criminosos, portanto, ninguém queria ser quilombola. Com os movimentos sociais, com o reconhecimento na Carta Magna, das identidades, e com a edificação de um direito étnico, é que há o empoderamento político dos quilombolas.

Em contraposição ao conceito de quilombo como algo longínquo e ligado ao rural, à natureza, indica-se ainda a existência de quilombos dentro do perímetro urbano, os chamados quilombos urbanos, que justamente por se distanciarem da noção engessada de quilombo, sofrem resistência quanto ao seu reconhecimento e titularização das terras.

Nesse contexto, vem-se apontar que, muito mais do que categorizar a partir do passado, a formação das identidades dos quilombolas tem a ver com o atual, com os conflitos que são enfrentados e pelas relações sociais que são formadas contemporaneamente. Como explana Barth (2000) as identidades e suas fronteiras étnicas são constituídas a partir dos conflitos.

Entende-se que a tradicionalidade, as identidades, os laços de solidariedade são reformulados constantemente, quando, por exemplo, em função dos que se opõe aos seus modos de viver, os povos e comunidades se reorganizam para lutar e resistir.

$\mathrm{Na}$ Amazônia, como ilustração, foi instituído o grupo denominado "Povos da Floresta", formado por quilombolas, indígenas, seringueiros, quebradeiras de coco, ribeirinhos, pescadores, dentre outros povos e comunidades, para enfrentar as ameaças que sofriam por parte de frentes desenvolvimentistas e conflitos latifundiários. Dentro dessas 
novas relações, parte das quebradeiras de coco, além de levantarem questões sobre gênero, também se autoafirmam quilombolas, o que pode exemplificar a complexidade da formação das identidades que está ligada ao presente, e não ao apego ao passado (LITLE 2002; ALMEIDA, 2004, 2008).

As definições, portanto, devem vir dos pontos de vista dos próprios grupos, de dentro, do que eles sentem, e não de análises externas que nunca vão alcançar o que realmente vivem. Somente os próprios povos e comunidades podem se autodefinir, decidir e dizer quem são, como desejam viver, quais são seus espaços sagrados, seus costumes, o que é essencial para a continuidade da sua identidade.

Diante dessas compreensões aqui expostas, não pode mais vigorar o apego às classificações pré-concebidas, antigas, que restringem as comunidades tradicionais. Compreende-se que todos os povos e comunidades têm direito, necessidade, de transformarse, nenhuma cultura é estática, imóvel. Como, e por que, os quilombolas deveriam então permanecer rígidos com o passar dos anos? Como, e por que, as comunidades de quilombos corresponderiam apenas aos descendentes, aos remanescentes dos que anteriormente eram assim considerados?

Destaca-se que, em contato, relações e conflitos com os demais grupos, as identidades e suas fronteiras são constantemente construídas, que o tradicional não tem a ver com permanecer imutável durante o tempo, e que, somente os próprios povos e comunidades devem se autodefinir e decidir sobre o seu futuro, como desejam viver. Esse direito fundamental à gestão da sua identidade não lhes deve ser furtado.

Como aponta Almeida (2002, p. 53):

É necessário que nos libertemos da definição arqueológica, da definição histórica stricto sensu e das outras definições que estão frigorificadas e funcionam como uma camisa-de-força, ou seja, da definição jurídica dos períodos colonial e imperial e até daquela que a legislação republicana não produziu, por achar que tinha encerrado o problema com a abolição da escravatura, e que ficou no desvão das entrelinhas dos textos jurídicos. A relativização dessa força do inconsciente coletivo nos conduz ao repertório de práticas e às autodefinições dos agentes sociais que viveram e construíram essas situações hoje designadas como quilombo.

Nota-se que "a conceituação do quilombo havida nos séculos passados perdeu sua eficácia jurídica, o que significa dizer que o conceito deve ser revisado. O pensamento jurídico tem que ser reinterpretado e assimilado pela mobilização política para ser positivado" (SHIRAISHI NETO, 2014a, p. 7). 


\section{ANÁLISE DO DIREITO À AUTODETERMINAÇÃO DAS COMUNIDADES QUILOMBOLAS NO JULGAMENTO DA ADI № 3239/2004 NO STF: ENTRE O DEGREDO, O ESQUECIMENTO E O DESCONHECIMENTO JURÍDICO}

Assim, percebe-se que os quilombolas passaram da condição de degredo para o esquecimento, sem ser contemplados pelo Estado no que tange à definição de direitos que pudessem alcançá-los nos 100 anos que sucederam a abolição da escravidão, até que, em 1988, foram trazidos de volta ao universo jurídico, mas de forma insuficiente. Sem se pensar adequadamente as especificidades atinentes à questão, passou a ocorrer, pela interpretação mais restrita que se está aqui criticando, um desconhecimento jurídico que não considera a identidade dos quilombolas, a autodeterminação.

O conceito de quilombos deve ser, nessas condições, ampliado e ressignificado para englobar as diferentes realidades existentes pelo país, não se limitando à incessante busca por resquícios arqueológicos que comprovem a ocupação temporal de um dado local para caracterizar a comunidade como quilombola e para titularizar o território, distanciando-se, também, da interpretação das comunidades quilombolas como necessariamente isoladas e como um grupo homogêneo (O’DWYER, 2010).

Dessa forma, faz-se importante ressaltar que em 1989 a Organização Internacional do Trabalho - OIT, instituiu a Convenção $\mathrm{n}^{\mathrm{o}}$. 169, um dos mais importantes instrumentos de proteção dos povos indígenas e tribais.

A Convenção $\mathrm{n}^{\circ}$. 169 da OIT constituiu o direito à autodeterminação (TOMEI; SWEPSTON, 1999). A partir de então, o critério para identificação do sujeito é a consciência, "é o que o sujeito diz de si mesmo, e em relação ao grupo ao qual pertence" (SHIRAISHI NETO, 2007). Trata-se de dar voz e poder para que os povos e comunidades se autoidentifiquem e para que possam gerir o seu futuro, e não sejam simplesmente desconsiderados por decisões e classificações que não são as suas. Considera-se, então, que a autodeterminação torna-se um direito fundamental para a continuidade, para a existência dos povos indígenas e comunidades tradicionais.

Questiona-se, entretanto, se o direito à autodeterminação tem sido observado pelo judiciário brasileiro e, especialmente, no que condiz a proteção das comunidades quilombolas?

\section{JULGAMENTO DA ADI Nº. 3239/2004: AVANCYS E RETROCESSOS}


O Partido da Frente Liberal - PFL, atualmente Democratas - DEM, propôs a Ação Direta de Inconstitucionalidade $\mathrm{n}^{\mathrm{o}}$. 3239/2004. O partido fundamentou o pedido de inconstitucionalidade do Decreto $\mathrm{n}^{\mathrm{o}}$. $4.887 / 03$ em razões de ordem formal e material. Primeiramente alegou que o Decreto seria formalmente inconstitucional em virtude da inexistência de lei anterior para regulamentar o art. 68 do ADCT, o que teria ocasionado violação à reserva legal.

Além disso, o autor da ADI afirmou que o Decreto seria materialmente inconstitucional em razão da inadequação do procedimento previsto em seu art. $13^{6}$ para desapropriação das terras dos quilombos, uma vez que o Estado deveria limitar-se a emitir os títulos de propriedade já que o próprio art. 68 do ADCT confere a propriedade definitiva aos remanescentes das comunidades dos quilombos.

Outro ponto que foi suscitado para fundamentar a inconstitucionalidade material diz respeito à adoção do critério da autoatribuição para identificar os remanescentes das comunidades dos quilombos, o que violaria a lógica constitucional.

O partido autor da ação expressou, ainda, que os critérios existentes para caracterização das terras de quilombos no Decreto, ou seja, a autodeterminação, seriam demasiadamente amplos e sujeitos a indicativos providenciados pelos próprios interessados, de forma que "a área cuja propriedade deve ser reconhecida constitui apenas e tão-somente o território em que comprovadamente, durante a fase imperial da história do Brasil, os quilombos se formaram" (Petição Inicial, ADI n. 3239).

Após a propositura da ação, houve manifestação do Advogado-Geral da União pelo não conhecimento da ação e improcedência dos pedidos em razão da falta de fundamentação, e parecer do Procurador-Geral da República pela improcedência da ação ${ }^{7}$.

Apesar da ADI ter sido proposta em 2004, o início da sessão de julgamento ocorreu somente em 18/04/2012, data em que o Relator do processo, Ministro Cezar Peluso, proferiu

\footnotetext{
${ }^{6}$ Decreto $\mathrm{n}^{\mathrm{o}}$. 4.887/03. Art. 13. Incidindo nos territórios ocupados por remanescentes das comunidades dos quilombos título de domínio particular não invalidado por nulidade, prescrição ou comisso, e nem tornado ineficaz por outros fundamentos, será realizada vistoria e avaliação do imóvel, objetivando a adoção dos atos necessários à sua desapropriação, quando couber.

${ }^{7}$ Ação Direta de Inconstitucionalidade em face do Decreto no ${ }^{0} 4.887 / 2003$, que regulamenta o procedimento para identificação, reconhecimento, delimitação, demarcação e titulação das terras ocupadas por remanescentes das comunidades dos quilombos de que trata o art. 68 do ADCT. Decreto que regulamenta o art. 14, IV, 'c', da Lei $\mathrm{n}^{\circ} 9.649 / 98$ e o art. $2^{\circ}$, III e parágrafo único, da Lei ${ }^{\circ} 7.668 / 88$. Inexistência de inconstitucionalidade formal. Necessidade de realização de desapropriação. Critério de autoatribuição para identificação das comunidades quilombolas e das terras a elas pertencentes. Estudos antropológicos atestam a adequação desse critério. Parecer pela improcedência da ação. Ementa. Parecer PGR. (BRASIL, 2004).
} 
o seu voto pela inconstitucionalidade formal - e também material em relação à alguns dispositivos - do Decreto $n^{\circ}$. 4.887/03. Votou, ainda, pela modulação dos efeitos da decisão para considerar válidos os títulos já emitidos até então.

Por sua vez, a Ministra Rosa Weber pediu vista do processo e proferiu o seu voto em 25/03/2015 pela improcedência da ADI e pela constitucionalidade do Decreto $\mathrm{n}^{\mathrm{o}}$. 4.887/03 por entender que o art. 68 do ADCT trata de direito fundamental das comunidades quilombolas e, portanto, o Decreto estaria apenas regulamentando um direito já existente e de aplicação imediata em sede constitucional.

Após esse voto, que foi considerado um avanço em relação ao posicionamento adotado pelo Ministro Cezar Peluso, o Ministro Dias Toffoli pediu vista e proferiu o seu voto em 09/11/2017. O Ministro Dias Toffoli posicionou-se pela procedência parcial da ADI a fim de conferir uma interpretação conforme ao $\S 2^{\circ}$ do art. $2^{\circ}$ do Decreto $n^{\circ} 4.887 / 2003^{8}$, e reforçou o estabelecimento do marco temporal para a titularização das terras comprovadamente ocupadas por remanescentes das comunidades dos quilombos na data da promulgação da CF/88, 05/10/1988, salvo os casos de perda ou suspensão da posse em razão de atos ilícitos praticados por terceiros.

Estavam, nesse contexto, abertas três possibilidades para o julgamento da ADI 3239: a tese da inconstitucionalidade formal, e também material em relação a alguns dispositivos, do Decreto $n^{\circ}$. 4.887/2003, defendida pelo Ministro Cezar Peluso; a tese da improcedência da ADI e constitucionalidade do Decreto $\mathrm{n}^{\mathrm{o}}$. 4.887/2003, defendida pela Ministra Rosa Weber; e a tese da procedência parcial da ADI, com o reforço do estabelecimento do marco temporal da promulgação da $\mathrm{CF} / 88$ para a titularização das áreas ocupadas e utilizadas pelas comunidades quilombolas, salvo os atos ilícitos praticados por terceiros, defendida pelo Ministro Dias Toffoli.

O Ministro Edson Fachin, próximo a votar, pediu vista do processo e o julgamento somente foi retomado em 08 de fevereiro de 2018, ocasião em que, por maioria de votos, a ADI 3239 foi julgada improcedente nos seguintes termos:

Preliminarmente, o Tribunal, por maioria, conheceu da ação direta, vencidos os Ministros Marco Aurélio e Ricardo Lewandowski. No mérito, o Tribunal, por maioria e nos termos do voto da Ministra Rosa Weber, que redigirá o acórdão,

\footnotetext{
${ }^{8}$ Decreto $n^{\circ} 4.887 / 03$. Art. $2^{\circ}, \S 2^{\circ}$. São terras ocupadas por remanescentes das comunidades dos quilombos as utilizadas para a garantia de sua reprodução física, social, econômica e cultural.
} 
julgou improcedentes os pedidos, vencidos o Ministro Cezar Peluso (Relator), e, em parte, os Ministros Dias Toffoli e Gilmar Mendes. Votaram, no mérito, os Ministros Marco Aurélio e Ricardo Lewandowski. Não votou o Ministro Alexandre de Moraes, por suceder o Ministro Teori Zavascki, que sucedera o Ministro Cezar Peluso. Presidiu o julgamento a Ministra Cármen Lúcia (BRASIL, 2018).

Realizar-se-á uma análise mais detalhada dos argumentos constantes nas três teses que permearam o julgamento da ADI 3239 no STF - os votos do Ministro Cezar Peluso, da Ministra Rosa Weber e do Ministro Dias Toffoli, - bem como realizar-se-á considerações acerca da sessão do Plenário do dia 08/02/2018 em si, e assim, da construção do entendimento que prevaleceu no julgamento da ação, com foco em se houve, ou não, prevalência do direito à autodeterminação.

\subsection{ANÁLISE DOS VOTOS DOS MINISTROS CEZAR PELUSO E ROSA WEBER}

O Ministro Cezar Peluso julgou a ação procedente com base na inconstitucionalidade formal e material do Decreto $\mathrm{n}^{\mathrm{o}}$. 4.887/03. Sobre a inconstitucionalidade formal, entendeu que houve violação aos princípios da legalidade e da reserva legal, uma vez que, em sua visão, o art. 68 do ADCT precisaria de uma lei para produzir efeitos. Dessa feita, não seria norma constitucional de eficácia plena e aplicabilidade imediata, necessitando de lei infraconstitucional para produzir seus efeitos.

Já a Ministra Rosa Weber entendeu, ao contrário, que o art. 68 do ADCT expressa direito fundamental das comunidades quilombolas e, portanto, é espécie de norma constitucional de eficácia plena e aplicabilidade imediata, não necessitando de lei infraconstitucional para produzir efeitos, nos termos do $\S 1^{\circ}$ do art. $5^{\circ}$ da $C F / 88^{9}$. Nesse sentido, divergiu do relator por entender que não houve violação aos princípios da legalidade e da reserva legal.

$\mathrm{Na}$ interpretação da Ministra, o Decreto $\mathrm{n}^{\circ}$. 4.887/03 nada mais fez do que regulamentar direito fundamental plenamente aplicável e presente no texto constitucional. Compreender a questão de outra forma seria retirar o seu próprio sentido, uma vez que "à norma constitucional - especialmente a definidora de direito fundamental - não pode ser atribuída exegese que lhe retire toda e qualquer densidade normativa” (BRASIL, 2015).

\footnotetext{
${ }^{9} \mathrm{CF} / 88$. Art. $5^{\circ}, \S 1^{\circ}$ As normas definidoras dos direitos e garantias fundamentais têm aplicação imediata.
} 
De tal maneira, a Administração estaria apenas exercendo o seu poder regulamentar. Vale apontar ainda que a Ministra fundamentou o seu posicionamento na jurisprudência da Corte Interamericana de Direitos Humanos. Como dispôs:

\begin{abstract}
Em convergência com esse entendimento a Corte Interamericana de Direitos Humanos, no julgamento do paradigmático caso Mayagna (Sumo) Awas Tingni, em 2001, ao declarar violados os artigos 21 (direito de propriedade) e 25 (direito a proteção judicial eficaz) da Convenção Americana sobre Direitos Humanos (Pacto de San José da Costa Rica) pelo Estado da Nicarágua porque, não obstante reconhecida, na Constituição daquele país, a propriedade comunal dos povos indígenas sobre as terras por eles ocupadas, jamais havia sido regulado procedimento específico para permitir o exercício desse direito. Sentenciou a Corte Interamericana que o Estado demandado - a Nicarágua - equipasse o seu direito interno com mecanismos para efetivar a delimitação e a titulação da propriedade dos povos tradicionais, em conformidade com seus costumes, fosse por medidas legislativas, fosse por medidas administrativas ou de qualquer outro caráter justamente por se tratar de direito fundamental (BRASIL, 2015, p.20-21).
\end{abstract}

Já o Ministro Cezar Peluso, quanto à inconstitucionalidade material, entendeu que o Decreto $n^{\circ} .4 .887 / 03$ possui vários dispositivos que estariam em conflito com a Constituição Federal, como os artigos $2^{\circ}$, parágrafos $1^{\circ}, 2^{\circ}$ e $3^{\circ}$, art. $7^{\circ}, \S 2^{\circ}$, art. $9^{\circ}$, art. 13 e art. 17.

Ademais, chama atenção a argumentação do Ministro quando reputou por inconstitucional o critério da autoatribuição e da autodefinição previstos no Decreto para caracterizar quem são os quilombolas e para indicar qual é o território que deverá ser demarcado. Em suas palavras, a Convenção no 169 seria posterior ao Decreto, envolveria outros grupos étnicos, e o critério da consciência não seria fundamental para a aquisição de direitos:

\footnotetext{
Nem se diga que o critério da autodefinição é imperativo determinado pela Convenção 169 da Organização Mundial do Trabalho - OIT, sobre povos indígenas e tribais, aprovada pelo Congresso Nacional mediante o Decreto legislativo 143/2002 e promulgada pelo Presidente da República pelo Decreto nº. 5051/2004. Tal tratado, além de ser posterior ao decreto impugnado e de cuidar de outros grupos étnicos, prevê o critério da "consciência" como fundamental à determinação dos grupos aos quais se aplicam suas disposições, e não para a aquisição - é bom que se diga -, deste ou daquele direito (BRASIL, 2012, p.41) (Grifo nosso).
}

Em oposição ao que estabelece o Ministro Cezar Peluso, vem-se esclarecer que a autodeterminação, como direito fundamental para a identificação dos povos indígenas e comunidades tradicionais, encontra-se, sim, vinculada à aquisição de direitos e garantias. Compreende-se que a autodeterminação é princípio fundamental no qual deve se fundar todos os demais direitos. Além do mais, impor outros critérios, que não o da autodeterminação, para 
conferir direitos e garantias aos povos e comunidades, seria retroagir à imposição de classificações externas aos grupos, a partir de perspectivas pré-concebidas.

$\mathrm{Na}$ verdade, considera-se um contrassenso reconhecer a autodeterminação, a consciência dos povos e comunidades sobre si e sobre o grupo a qual pertencem para a sua identificação como tradicionais, mas compactuar com outros requisitos, que não o da voz e decisão dos próprios povos e comunidades, para aquisição e exercício de direitos.

Outro ponto que deve ser destacado é que a Convenção $n^{\circ} .169$ da OIT, de 27/06/89, entrou em vigor internacionalmente em 05/09/91 e para o Brasil em 25/07/03, já que o governo brasileiro depositou o seu instrumento de ratificação junto ao Diretor Executivo da OIT em $25 / 07 / 02^{10}$, nos termos de seu artigo $38^{11}$.

Nessa perspectiva, o argumento utilizado pelo Ministro Cezar Peluso de que a Convenção é posterior ao Decreto $n^{\circ} .4 .887$ de 20/11/03 não é adequado, uma vez que, as obrigações advindas da ratificação da Convenção $\mathrm{n}^{\mathrm{o}}$. 169 da OIT já estavam em vigor internacionalmente para o Brasil quando da sua edição. Dessa forma, o Decreto $n^{\circ} .4 .887$ de 20/11/2003 é posterior à vigência das obrigações advindas da Convenção no 169 para o Brasil, e seu conteúdo deve se ater sim a este tratado internacional.

Já o fato da Convenção $n^{\circ}$. 169 tratar dos povos indígenas e tribais, não exclui, conforme mencionando anteriormente, sua aplicação aos diversos grupos étnicos existentes no Brasil, como os quilombolas, por exemplo (SHIRAISHI NETO, 2014b). O objetivo da Convenção, ao adotar essa terminologia, era abranger a maior quantidade de grupos nos diferentes países e não restringir a sua incidência (TOMEI; SWEPSTON, 1999).

A Ministra Rosa Weber, por sua vez, reputou constitucional o critério da autoatribuição e da autodefinição previstos no Decreto $n^{\circ}$. 4.887/03. Na sua argumentação a Ministra ressaltou inclusive o conceito de identidade existente na Convenção $n^{\circ} .169$ da OIT.

\footnotetext{
${ }^{10}$ Decreto $\mathrm{n}^{\circ}$ 5051/04. Considerando que o Congresso Nacional aprovou, por meio do Decreto Legislativo $\mathrm{n}^{\circ}$ 143, de 20 de junho de 2002, o texto da Convenção no 169 da Organização Internacional do Trabalho - OIT sobre Povos Indígenas e Tribais, adotada em Genebra, em 27 de junho de 1989; Considerando que o Governo brasileiro depositou o instrumento de ratificação junto ao Diretor Executivo da OIT em 25 de julho de 2002; Considerando que a Convenção entrou em vigor internacional, em 5 de setembro de 1991, e, para o Brasil, em 25 de julho de 2003, nos termos de seu art. 38; DECRETA: Art. $1^{\circ}$ A Convenção ${ }^{\circ} 169$ da Organização Internacional do Trabalho - OIT sobre Povos Indígenas e Tribais, adotada em Genebra, em 27 de junho de 1989, apensa por cópia ao presente Decreto, será executada e cumprida tão inteiramente como nela se contém.

${ }^{11}$ Convenção ${ }^{\circ} 169$ OIT. Artigo 38. 1. A presente Convenção somente vinculará os Membros da Organização Internacional do Trabalho cujas ratificações tenham sido registradas pelo Diretor-Geral. 2. Esta Convenção entrará em vigor doze meses após o registro das ratificações de dois Membros por parte do Diretor-Geral. 3. Posteriormente, esta Convenção entrará em vigor, para cada Membro, doze meses após o registro da sua ratificação.
} 
Contudo, apesar do voto da Ministra Rosa Weber defender a aplicação da Convenção $\mathrm{n}^{\mathrm{o}} .169$ da OIT e da autodeterminação, de elencar avançadas decisões da Corte Interamericana de Direitos Humanos ${ }^{12}$ (BRASIL, 2015), e de ter se posicionado pela improcedência da ADI, verifica-se que, ao final, a Ministra mencionou, em semelhança ao Ministro Dias Toffoli, a necessidade de se ter um elemento objetivo para a titulação das terras, relacionando um critério externo às comunidades quilombolas e que limita a autodeterminação.

A Ministra Rosa Weber ligou a aplicação do art. 68 do ADCT, e, assim, a definição de quilombos, à uma ocupação continuada do espaço datada em 05/10/1988. In verbis:

\begin{abstract}
Pontuo, por oportuno, que a ostentação de uma identidade - que pode ser autoatribuída - não se confunde com a satisfação dos critérios objetivos exigidos pelo texto constitucional para o reconhecimento da titularidade do direito assegurado no art. 68 do ADCT - que é, pelo menos em uma de suas dimensões, um direito real de propriedade. Assim, para os fins específicos da incidência desse dispositivo constitucional transitório, além de uma dada comunidade ser qualificada como remanescente de quilombo - elemento subjetivo que reside no âmbito da autoidentificação -, mostra-se necessária a satisfação de um elemento objetivo, empírico: a reprodução da unidade social que se afirma originada de um quilombo há de estar atrelada a uma ocupação continuada do espaço ainda existente, em sua organicidade, em 05 de outubro de 1988, de modo a se caracterizar como efetiva atualização histórica das comunidades dos quilombos (BRASIL, 2015, p.4041) (Grifo nosso).
\end{abstract}

De acordo com esse entendimento, seriam olvidadas as comunidades de quilombos que foram ressurgindo, em um já comentado processo de etnogênese, somente a partir da $\mathrm{CF} / 88$ e do empoderamento político das suas identidades, por exemplo.

Observa-se que a Ministra Rosa Weber, em seu voto, expressa decisões da CIDH que sentenciaram países a editar normas, legislações e procedimentos administrativos para regulamentar e viabilizar os direitos dos povos e comunidades. Não se opõe, desse modo, à elaboração dessas normas para concretizar as garantias dos povos e comunidades e nem se refuta as possíveis consequências positivas que podem advir dessa regulamentação, como a maior exigibilidade dos direitos. Entretanto, deve-se, no presente artigo científico, ressalvar que tal normatização, tal regulamentação, deve ser baseada no princípio fundamental da autodeterminação.

\footnotetext{
${ }^{12}$ Citou o caso da comunidade Moiwana v. Suriname (2005) e o caso da comunidade Saramaka v. Suriname (2007) (BRASIL, 2015, p. 42).
} 
Qualquer interpretação diversa desta, que imponha requisitos que não a autodeterminação, tanto para identificação dos povos indígenas e comunidades tradicionais, quanto para a aquisição de direitos, estaria ferindo a Convenção $\mathrm{n}^{\circ} .169$ da OIT, tratado internacional de direitos humanos, e implicaria em restrições e riscos aos grupos tradicionais e não na sua ampla e devida proteção.

\subsection{ANÁlisE DO VOTO DO MINISTRO DIAS TOFFOLI E DA SESSÃO DE CONCLUSÃO DO JULGAMENTO}

O Ministro Dias Toffoli proferiu seu voto vista em 09/11/2017 e, ao final do julgamento da ADI 3239, em 08/02/18, restou parcialmente vencido. Isso porque utilizou alguns dos argumentos que acabaram prevalecendo no julgamento, no entanto, ao defender a tese do marco temporal, julgou a ADI parcialmente procedente no intuito de conferir interpretação conforme ao Decreto $n^{\circ} 4.887 / 2003$.

Assim, o Ministro, após fazer uma introdução retomando as alegações do autor, as considerações dos Ministros que o precederam, bem como a inserção do direito dos quilombolas na Constituição Federal de 1988 e a evolução normativa da regulamentação desse direito, afastou a alegação de inconstitucionalidade formal do Decreto $n^{\circ}$. 4.887/2003.

Sustentou que o decreto em questão não padecia de vício de inconstitucionalidade formal, uma vez que seu conteúdo encontra-se dentro dos preceitos trazidos pela $\mathrm{CF} / 88$, pela legislação que o precede e também pela Convenção no 169 da OIT da qual o Brasil é signatário.

Vale relembrar que a Convenção $\mathrm{n}^{\mathrm{o}}$. 169 da OIT trouxe uma obrigação internacional ao Estado Brasileiro de atuar interna e externamente em conformidade com os seus preceitos. Assim, ao editar o Decreto $n^{\circ}$. 4.887/2003, o Estado Brasileiro, reconhecendo o princípio da autodeterminação e o critério da autoatribuição, nada mais fez do que dar concretude ao disposto na Convenção $\mathrm{n}^{\mathrm{o}}$. 169 da OIT que já estava em vigor internacionalmente para o Brasil quando da edição do decreto em questão.

Para finalizar a questão da constitucionalidade formal do Decreto $n^{\circ} .4 .887 / 2003$, o Ministro Dias Toffoli ressaltou que o art. 68 do ADCT “é dotado de eficácia plena e aplicabilidade imediata, não necessitando, em verdade, de intermediação de lei formal para a regulamentação dos procedimentos necessários à concretude do comando constitucional" 
(BRASIL, 2017, p. 14). Tal posicionamento está de acordo com o que foi argumentado pela Ministra Rosa Weber.

Sobre a questão do critério da autoatribuição, o Ministro Dias Toffoli entendeu como perfeitamente adequado, tendo em vista que compete aos indivíduos o reconhecimento e a identificação do pertencimento ao grupo. Disse também que se trata de determinação que está em consonância com as disposições da Convenção $n^{\circ} .169$ da OIT. Dessa feita, o Ministro Dias Toffoli concluiu que não havia inconstitucionalidade no art. $2^{\circ}$, caput e $\S 1^{\circ}$, do Decreto $\mathrm{n}^{\mathrm{o}}$. 4.887/03, que adota o critério da autodefinição como fundamental à identificação dos remanescentes das comunidades dos quilombos.

Entretanto, o ponto que abriu a divergência em seu voto diz respeito à ênfase quanto à utilização do marco temporal da promulgação da Constituição Federal, em 05 de outubro de 1988, para definir a titularização das terras que estivessem ocupadas por remanescentes das comunidades de quilombos naquela data.

Ao utilizar a tese do marco temporal, o Ministro Dias Toffoli julgou a ADI 3239 parcialmente procedente nos seguintes termos:

\begin{abstract}
No meu sentir, o direito estabelecido pelo art. 68 do ADCT é o direito das comunidades remanescentes de quilombo de terem a propriedade das terras por elas ocupadas quando da edição da Constituição, aqui incluídas as utilizadas nessa data para a garantia de sua reprodução física, social, econômica e cultural. Entendo que essa é a interpretação que deriva diretamente do texto constitucional e que é passível de ser garantida e realizada pelo Estado brasileiro; nem mais, nem menos e sem idealismos ou falsas promessas. Ante o exposto, voto no sentido de julgar parcialmente procedente a presente ação direta de inconstitucionalidade, tão somente para conferir interpretação conforme ao $\S 2^{\circ}$ do art. $2^{\circ}$ do Decreto $n^{\circ} 4.887$, de 20 de novembro de 2003, no sentido de esclarecer, nos termos do art. 68 do ADCT, que somente devem ser titularizadas as áreas que estavam ocupadas por remanescentes das comunidades dos quilombos, inclusive as efetivamente utilizadas para a garantia de sua reprodução física, social, econômica e cultural, na data da promulgação da Constituição (5 de outubro de 1988), salvo comprovação, por todos os meios de prova juridicamente admitidos, da suspensão ou perda da posse em decorrência de atos ilícitos praticados por terceiros (BRASIL, 2017, p. 36).
\end{abstract}

Compreende-se, todavia, que a tese do marco temporal, que acabou sendo superada no curso da sessão de julgamento da ADI 3239 em 08/02/18, não contribui para a efetivação do direito dos quilombolas à terra, não respeita o princípio da autodeterminação e impõe um requisito de difícil comprovação para as comunidades.

Indica-se que a interpretação do marco temporal revela uma visão dos quilombos como algo vinculado ao passado, que está fadado a deixar de existir, e que deveria 
permanecer congelado no tempo. Levar em conta somente os quilombos que existiam no momento da promulgação da $\mathrm{CF} / 88$, representa uma violência que retira o propósito de proteção, de garantia de direitos, que tinha o Constituinte ao tentar reparar uma injustiça e um longo período de invisibilidade das comunidades quilombolas. Uma vez que, de tal maneira, são fechadas as portas para as diversas situações de etnogênese, de ressurgimento das comunidades, além de outros.

Desse modo, em virtude da divergência existente no julgamento da ADI 3239, o Ministro Edson Fachin pediu vista dos autos e o julgamento foi retomado e concluído na sessão do plenário ocorrida em 08/02/18. O Ministrou Edson Fachin posicionou-se pela total improcedência da ADI 3239. Concluiu a ausência da inconstitucionalidade formal e material e acatou o parecer da PGR reconhecendo a autoatribuição como ponto de partida do processo de regularização das terras.

O Ministro Edson Fachin também se ateve sobre o tema do marco temporal e considerou que a aplicação de um direito fundamental contido na Constituição Federal de 1988 não deve ser restringida às comunidades que estavam sob posse dos territórios em 05/10/1988. O Ministro discorreu sobre a tipologia da norma, que para ele não afasta a aplicação desse direito fundamental às comunidades quilombolas ainda desconhecidas, e sobre a falta de registros que atestem a ocupação, já que a formação de quilombos era considerada crime, o que não pode inviabilizar a aplicação de direitos.

Enfatizou ainda que, por se tratar se um direito fundamental, deveria ser observado o princípio da máxima eficácia das normas constitucionais. Citou também os artigos 215 e 216 da $\mathrm{CF}$, segundo os quais os modos de criar, fazer e viver dessas comunidades se apresentam como patrimônio cultural imaterial brasileiro, dentre outros argumentos.

O Ministro Luís Roberto Barroso em seu voto posicionou-se quanto à legalidade do Decreto $n^{\circ} .4 .887 / 03$, por entender que este apenas concretiza a $C F / 88$ e que não cria nenhuma norma nova. Tal qual o Ministro Fachin, o Ministro Barroso também reconheceu a autoatribuição, e expôs que tal critério não consubstanciava na legalização de fraudes, que estas podiam ser identificadas no decorrer do processo de regularização das terras. Afirmou então a legalidade formal e material do decreto em discussão.

O Ministro Barroso também tratou sobre a tese do marco temporal e dispôs que o direito deve ser atribuído tanto às comunidades que estavam em sua área em período 


\section{ANÁLISE DO DIREITO À AUTODETERMINAÇÃO DAS COMUNIDADES QUILOMBOLAS NO JULGAMENTO DA ADI № 3239/2004 NO STF: ENTRE O DEGREDO, O ESQUECIMENTO E O DESCONHECIMENTO JURÍDICO}

constitucional quanto àquelas que foram retiradas dos seus territórios mas mantiveram vínculo econômico e cultural e pretendem retornar, independente de esforço físico e de ações.

O Ministro Ricardo Lewandowski, por sua vez, assim como o Ministro Barroso e o Ministro Fachin, se posicionou a favor da autoatribuição, mas, ao rechaçar a possibilidade de fraudes, disse que a autoatribuição não seria o único critério utilizado, seria apenas o ponto de partida para o preenchimento de demais requisitos no processo de regularização de terras. Tratando sobre a validade do decreto, o Ministro Lewandowski, também entendeu que o decreto apenas traz procedimentos administrativos para execução de um comando constitucional.

Sobre o marco temporal, o Ministro Lewandowski corroborou com as afirmações já feitas de que não se pode atribuir o ônus da prova sobre a posse dos quilombolas dos territórios na data de 05/10/1988. Ainda posicionou-se contra a solução apontada pelo Ministro Dias Toffoli e julgou improcedente a ação.

Já o Ministro Gilmar Mendes afirmou que os direitos fundamentais devem ser regulamentados por leis e que estas são elaboradas pelo parlamento que tem representatividade para tanto. Ao final acompanhou integralmente o voto do Ministro Dias Toffoli.

O Ministro Luiz Fux e o Ministro Celso de Mello, assim como os Ministros Fachin, Barroso e Lewandowski, reconheceram o critério da autoatribuição, a legitimidade do decreto e a improcedência da ação.

O Ministro Fux explanou, contudo, que a autoatribuição não seria o único parâmetro para a definição da identidade quilombola tendo em vista a prevenção contra fraudes, e que não há aplicabilidade do marco temporal, porque a $\mathrm{CF} / 88$ não traz em seu texto nenhuma referência à datas, e porque a história de discriminação vivida pelos quilombolas não permitiria tal prática.

O Ministro Celso de Mello comentou, ademais, acerca da Convenção $n^{\circ} .169$ da OIT, que legitima o Decreto $\mathrm{n}^{\circ}$. 4.887/03, e que tal Convenção tem o status de matéria constitucional, compondo o bloco de constitucionalidade, não sendo supralegal.

Já o Ministro Marco Aurélio argumentou que o artigo constitucional é autoaplicável e que demandava diretrizes para tanto, diretrizes que foram legitimamente preenchidas pelo decreto em análise. Votou pela improcedência da ADI 3239. Por último, a Ministra Cármem 
Lúcia, a seu turno, votou pela total improcedência da ADI 3239 e pela manutenção do Decreto $\mathrm{n}^{\mathrm{o}}$. 4.887/03. Ao final a ADI 3239, pela maioria dos votos, foi considerada improcedente, o Decreto $n^{\circ}$. 4.887/03 foi mantido, e foi rechaçada a aplicação da tese do marco temporal.

\section{CONSIDERAÇÕES FINAIS}

Conforme o que foi exposto, compreende-se que a questão dos quilombos no Brasil passou pelo degredo - pelo qual os quilombolas eram criminalizados e definidos por um conjunto de fatores alheios à sua consciência sobre si mesmos - pelo esquecimento - pois após a abolição da escravatura, acreditando-se que não haveriam mais quilombos, não existia mais previsão legal sobre esses grupos - e pelo desconhecimento jurídico - já que a $\mathrm{CF} / 88$, que traz no artigo 68 do ADCT o termo remanescente das comunidades de quilombos, atrelando portanto a definição de quilombo ao passado, à elementos pré-concebidos, encrustados em nosso imaginário, sobre o que deve ser o quilombo, aquilo que restou.

Destaca-se, porém, o direito à autodeterminação edificado pela $\mathrm{CF} / 88$ e pela Convenção $\mathrm{n}^{\mathrm{o}}$. 169, - em consonância às demandas dos movimentos sociais - a partir do qual passa a valer o que o sujeito diz de si mesmo e sobre o seu grupo, sendo afastadas, dessa maneira, classificações externas e etnocêntricas. Ressalta-se que as comunidades quilombolas, tal qual qualquer outro grupo, têm o direito à transformação, têm a dinamicidade da cultura, passam por processos de etnogênese, estabelecimento de novas relações, dentre outros. Os povos e comunidades são então os únicos capazes de gerir os seus próprios destinos, de falar sobre si mesmos.

Nesse contexto, observa-se que, quanto ao julgamento da ADI $n^{\circ} .3239$, que discutiu a constitucionalidade do Decreto $n^{\circ}$. 4.887/03 sobre o procedimento para identificação, reconhecimento, delimitação, demarcação e titulação das terras ocupadas pelo quilombolas, os Ministros do STF apresentaram posicionamentos divergentes. Alguns aqui considerados como avanços e outros como retrocessos, envolvendo a definição de quilombo e a autodeterminação.

De forma resumida, pairavam nesse julgamento três posicionamentos centrais: pela procedência da ação, pela improcedência da ação com a declarada constitucionalidade do Decreto, e pela procedência parcial da ação com a imposição, para além da autodeterminação, 
do requisito do marco temporal, ou seja, que as comunidades provassem estar no local na data de $05 / 10 / 88$, que é a data da promulgação da $\mathrm{CF} / 88$, para que fossem reconhecidos os seus territórios.

Ao final prevaleceu a improcedência da ação, sem o estabelecimento do citado marco temporal. Entende-se no presente artigo científico que, caso fosse estabelecido o marco temporal, estaria ferido o direito à autodeterminação, e seria legalizado um requisito impeditivo à titularização dos territórios, já que os quilombolas foram por muito tempo criminalizados e marginalizados, e não possuem, em sua maioria, prova da posse na data estipulada. Seria o mesmo que perpetuar uma injustiça histórica.

Contudo, apesar de não ser acatada a tese do marco temporal, alguns Ministros argumentaram que a autodeterminação seria apenas o início de vários requisitos e procedimentos que deveriam ser cumpridos para a titularização da terra. Em virtude disso, há de se atentar para que esses procedimentos e requisitos não configurem impedimentos e falta de celeridade na efetivação dos direitos das comunidades quilombolas, não concretizando a autodeterminação.

\section{REFERENNCIAS}

ALMEIDA, Alfredo Wagner Berno de. Os quilombos e as novas etnias. In: LEITÃO, Sérgio. Direitos Territoriais das comunidades negras rurais. São Paulo: Isa, 1999.

Os quilombos e as novas etnias. In: O’DWYER, Eliana Carneiro (Org.). Quilombos: identidade étnica e teritorialiodade. Rio de Janeiro: Editora FGV, 2002.

Terras tradicionalmente ocupadas: processos de territorialização e movimentos sociais. Revista Brasileira de estudos Urbanos e regionais, São Paulo, Vol. 6, n. 1, 2004.

. Terras de quilombos, terras indígenas, "babaçuais livres", "castanhais do povo", faxinais e fundos de pastos: terras tradicionalmente ocupadas.2. ed. Manaus: PPGSCAUFAM, 2008.

BANDEIRA, Maria de Lourdes. Terras negras: invisibilidade expropriadora. Textos e debates: Florianópolis: Núcleo de Estudos sobre Identidade e Relações Interétnicas, a.1 Vol. $2,1991$.

BARTH, Fredrik. O guru, o inciador e outras variações antropológicas. Rio de Janeiro: Contra Capa Livraria, 2000. 
BRASIL, Procuradoria Geral da República - PGR. ADI 3239. Parecer. Procurador-Geral da República Claudio Fonteles, parecer em 17/09/2004.

BRASIL, Supremo Tribunal Federal - STF. ADI 3239. Voto. Rel. Min. Antonio Cezar Peluso, julgamento em 18/04/2012.

ADI 3239. Voto vista. Min. Rosa Maria Weber Candiota da Rosa, julgamento em $25 / 03 / 2015$.

. ADI 3239. Voto vista. Min. José Antonio Dias Toffoli, julgamento em 09/11/2017.

ADI 3239. Decisão. Plenário, julgamento em 08/02/2018.

LITLE, Paul E. Territorios sociais e povos tradicionais no Brasil: por uma antropologia da territorialidade. Série Antropologia, n. 322. Brasília: Departamento de Antropologia, 2002.

O'DWYER, Eliana Carneiro. Terras de Quilombo no Brasil: direitos territoriais em construção. In: ALMEIDA, Alfredo Wagner Berno de; et al (Orgs). Cadernos de debates Nova Cartografia Social: Territórios quilombolas e conflitos. Manaus: Projeto Nova Cartografia Social da Amazônia - UEA Edições, 2010.

SHIRAIHI NETO, Joaquim. Direitos dos povos e das comunidades tradicionais no Brasil: declarações, convenções internacionais e dispositivos jurídicos definidores de uma política nacional. Manaus: UEA, 2007.

Os quilombos como novos "sujeitos de direito": processo de reconhecimento e impasses. Cadernos UNDB, São Luís, v.4, Jan/Dez, 2014a.

Convenção 169 da oit: "quando a forma determina o conteúdo", 2014b. Disponível

em: $\quad<$ http://acervo.racismoambiental.net.br/2014/09/01/convencao-169-da-oit-quando-aforma-determina-o-conteudo-por-joaquim-shiraishi-neto/>. Acesso em: 28 abr. 2017.

SOUZA FILHO, Carlos Frederico Marés de. Direitos dos povos indígenas na América Latina. In: SHIRAISHI NETO, Joaquim (Org.). Novos direitos na América Latina: estudo comparativo como instrumento de reflexão do próprio Direito. São Luís: EDUFMA, 2016.

TOMEI, Manuela; SWEPSTON, Lee. Povos indígenas e tribais: guia para a aplicação da convenção n. 169 da OIT. Brasília: Organização Internacional do Trabalho, 1999. 